\title{
Exercise training in pediatric patients with end-stage renal disease
}

\author{
Monique van Bergen • Tim Takken • Raoul Engelbert • \\ Jaap Groothoff • Jeroen Nauta • Koen van Hoeck • \\ Paul Helders • Marc Lilien
}

Received: 11 June 2008 /Revised: 27 August 2008 / Accepted: 28 August 2008 / Published online: 7 October 2008

(C) The Author(s) 2008. This article is published with open access at Springerlink.com

\begin{abstract}
The objective of this study was to determine the feasibility and efficacy of an exercise training program to improve exercise capacity and fatigue level in pediatric patients with end-stage renal disease (ESRD). Twenty children on dialysis intended to perform a 12-week graded community-based exercise program. Exercise capacity and
\end{abstract}

M. van Bergen $\cdot$ T. Takken $(\bowtie) \cdot$ R. Engelbert $\cdot$ P. Helders

Department of Pediatric Physical Therapy and Exercise

Physiology, Wilhelmina Children's Hospital,

University Medical Center Utrecht,

Room KB.02.056, P.O. Box 85090, 3508 AB Utrecht,

The Netherlands

e-mail: t.takken@umcutrecht.nl

R. Engelbert

Department of Physical Therapy, University of Applied Sciences, Amsterdam School of Health Professions,

Amsterdam, The Netherlands

J. Groothoff

Department of Pediatric Nephrology, Emma Children's Hospital,

Academic Medical Centre,

Amsterdam, The Netherlands

J. Nauta

Department of Pediatric Nephrology, Erasmus-MC,

Sophia's Children Hospital,

Rotterdam, The Netherlands

K. van Hoeck

Department of Pediatric Nephrology,

University Hospital Antwerp,

Antwerp, Belgium

\section{Lilien}

Department of Pediatric Nephrology,

Wilhelmina Children's Hospital,

University Medical Center Utrecht,

Utrecht, The Netherlands fatigue level were studied; muscle force and health-related quality of life were secondary outcomes. All outcomes were measured at baseline $(T=0)$ and after intervention $(T=1)$. Fourteen of the 20 patients $(70 \%)$ either did not start the program or did not complete the program. Of these patients, seven did not complete or even start the exercise program because of a combination of lack of time and motivational problems. Six patients were not able to continue the program or were unable to do the follow-up measurements because of medical problems. Exercise capacity and muscle strength was higher after the exercise program in the children who completed the training. In conclusion, exercise training is difficult to perform in children with ESRD and is not always feasible in real-life situations for many children with ESRD.

Keywords Exercise capacity · Muscle strength . Health-related quality of life - Exercise therapy .

Chronic kidney failure $\cdot$ Rehabilitation .

Oxygen consumption

\section{Introduction}

Children with end-stage renal disease (ESRD) are characterized by severe exercise intolerance [1-3]. Several studies have investigated the effect of physical exercise on exercise capacity in adults with ESRD. A recent review article described positive effects of 12 exercise training programs in adult patients on hemodialysis [4]. To our knowledge, effects of exercise training in children with ESRD have not been published. Therefore, the aim of this study was to determine the feasibility and efficacy of an exercise training program in children with ESRD. 


\section{Methods}

Patients and design

Dutch-speaking children between 8 and 18 years of age with a diagnosis of ESRD and treated with either hemodialysis (HD) or peritoneal dialysis (PD) for more than 3 months were included. Patients were recruited from the pediatric nephrology outpatient clinics of the University Children's Hospitals of Utrecht, Amsterdam, Rotterdam, the Netherlands; and Antwerp, Belgium. In total, 25 children were invited to participate, of whom 20 patients intended to participate in this study. The parents of five children refused to participate due to personal or logistic reasons.

Informed consent was obtained from the parents, and from the children if they were older than 12 years of age. The study was approved by the medical ethics review committee of all participating medical centers.

All children were tested in their local hospital by the same research staff (MvB, TT and RHE) using the same equipment to reduce bias. To eliminate a possible influence of a recent hemodialysis session on exercise capacity, patients were tested immediately prior to hemodialysis treatment.

Six-min walk test (6MWT)

The 6MWT was performed on a 20-m track in a straight hospital corridor. Patients were instructed to cover the largest possible distance in $6 \mathrm{~min}$ at a self-chosen walking speed. Every min, the patients were encouraged in a standardized way [5] and time, recorded with a stopwatch, and the time was called every min.

\section{Cardiopulmonary exercise test}

The patients performed a progressive cardiopulmonary exercise test (CPET) to exhaustion using an electronically braked cycle ergometer (Lode Corrival, Lode BV, Groningen, the Netherlands) and a calibrated respiratory gas analysis system (Cortex Metamax $\mathrm{B}^{3}$, Cortex Medical, Leipzig, Germany), as described previously [6]. During the test, peak oxygen uptake $\left(\dot{V}_{\mathrm{O}_{2 \text { peak }}}\right)$, peak work rate $\left(\mathrm{W}_{\text {peak }}\right)$ and peak heart rate $\left(\mathrm{HR}_{\text {peak }}\right)$ were determined.

\section{Muscle strength}

Muscle strength was measured with a hand-held dynamometer (Citec dynamometer 3001, C.I.T.-Technics, Groningen, the Netherlands) in eight muscle groups (elbow flexors and extensors, knee flexors and extensors, shoulder abductors, grip strength, hip flexors, and dorsiflexors of the ankle joint) as described by Beenakker et al. [7].
Fatigue

Fatigue was measured with the "subjective fatigue" subscale of the self-report questionnaire Checklist Individual Strength-20 (CIS-20). The CIS-20 assesses fatigue in the 2 weeks before the assessment [8].

Health-related quality of life (HRQoL)

The Child Health Questionnaire Parent Form 50 (CHQ) was used as a proxy report of HRQoL [9] and was filled out by the parents. A higher score reflects a better HRQoL.

\section{Exercise training program}

The graded community-based exercise program consisted of 12 weeks training (24 supervised sessions, twice a week) aimed to improve exercise capacity and muscle strength. Using the data from the baseline exercise test, the exercise intensity was individually prescribed for each patient. Starting after the sixth week of the intervention, patients were instructed to perform exercises at home once a week. The exercise sessions were held in community practices supervised by local pediatric physiotherapists instructed by the research staff to warrant the uniformity of the training program. The 50-min sessions included a 5-min warm-up period. Each session consisted of aerobic training (with an intensity ranging from $55-90 \%$ of $\mathrm{HR}_{\text {peak }}$ ), resistance exercises, and active games. In the final 4 weeks of the trainings intervention, 10 min of interval exercise was included in the sessions. The session ended with $5 \mathrm{~min}$ of cool down exercises. The resistance training consisted of exercises without heavy weights. A detailed description of the program is available from the corresponding author. The exercise training program was completed when the patients took part in at least 20 sessions with no break longer than 3 weeks.

\section{Statistical analysis}

Because of the small patient group, only descriptive statistics were used. Baseline data between patients who completed the exercise program and those who dropped out were compared using the Mann-Whitney $U$ test.

\section{Results}

At baseline, one patient terminated the test prematurely because of breathing difficulties when using the facemask and thus did not meet the criteria for maximal effort. Patient characteristics are presented in Table 1.

One patient who completed the exercise program could not perform the follow-up evaluation because of disease- 
Table 1 Patient characteristics and pre- and posttraining evaluation

\begin{tabular}{|c|c|c|c|c|c|c|c|c|c|c|c|c|c|c|c|c|}
\hline \multirow[t]{2}{*}{ Patient } & \multirow[t]{2}{*}{$\begin{array}{l}\text { Age } \\
\text { (years) }\end{array}$} & \multirow[t]{2}{*}{$\begin{array}{l}\text { BMI } \\
\text { (Z-score) }\end{array}$} & \multirow[t]{2}{*}{ Cause of renal failure } & \multirow[t]{2}{*}{ Mode of dialysis } & \multicolumn{2}{|c|}{$\begin{array}{l}\mathrm{W}_{\text {peak }} \\
\text { (Watt) }\end{array}$} & \multicolumn{2}{|c|}{$\begin{array}{l}\dot{V} \mathrm{O}_{2 \text { peak }} / \mathrm{kg} \\
(\mathrm{ml} / \mathrm{kg} / \mathrm{min})\end{array}$} & \multicolumn{2}{|c|}{$\begin{array}{l}\text { Muscle strength } \\
\text { (N) }\end{array}$} & \multicolumn{2}{|c|}{$\begin{array}{l}6 \mathrm{MWT} \\
(\mathrm{m})\end{array}$} & \multicolumn{2}{|c|}{$\begin{array}{l}\text { HRQoL } \\
\text { (total score) }\end{array}$} & \multicolumn{2}{|c|}{ CIS-20 } \\
\hline & & & & & Pre & Post & Pre & Post & Pre & Post & Pre & Post & Pre & Post & Pre & Post \\
\hline 1 & 17.6 & -0.46 & Congenital disorder & HD & 150 & 180 & 35.0 & 41.0 & 1896 & 1976 & 600 & 630 & - & 174 & 28 & 12 \\
\hline 2 & 8.8 & 0.69 & $\begin{array}{l}\text { Focal Segmental } \\
\text { Glomerulosclerosis }\end{array}$ & HD & 42.5 & - & 33.0 & 33.0 & 777 & 522 & 455 & 420 & 163 & 162 & - & - \\
\hline 3 & 13.0 & -0.24 & Congenital disorder & CAPD & 60 & 75 & 29.0 & 33.7 & 770 & 853 & 524 & 500 & 144 & 136 & - & - \\
\hline 4 & 10.6 & 0.02 & Unknown & NIPD & 120 & 135 & 43.0 & 54.0 & 891 & 1031 & 591 & 561 & 167 & 176 & 17 & 15 \\
\hline 5 & 13.2 & 1.36 & Congenital disorder & CAPD & 74 & 77.5 & 23.0 & 24.0 & 881 & 1006 & 560 & 604 & 146 & 147 & 46 & 16 \\
\hline \multicolumn{5}{|c|}{ Mean \pm SD change $(\%)$} & \multicolumn{2}{|c|}{$15.6 \pm 8.9$} & \multicolumn{2}{|c|}{$12.6 \pm 10.3$} & \multicolumn{2}{|c|}{$2.4 \pm 20$} & \multicolumn{2}{|c|}{$-0.9 \pm 6.8$} & \multicolumn{2}{|c|}{$0.0 \pm 4.5$} & \multicolumn{2}{|l|}{-} \\
\hline
\end{tabular}

$H D$ hemodialysis, $C A P D$ continuous ambulatory peritoneal dialysis, NIPD nocturnal intermittent peritoneal dialysis

related physical problems. Fifteen patients did not complete the exercise program and took part in an average of seven sessions. Of these patients, seven did not complete or even start the exercise program because of a combination of lack of time and motivational problems. Six patients were not able to continue the program or were unable to perform the follow-up measurements because of medical problems related to their kidney disease. One patient received a kidney transplantation during the intervention period, and one patient terminated the exercise program because of family holidays. It is important to note that none of the patients stopped the exercise program because of adverse effects of the exercise program itself, such as musculoskeletal injuries or increased levels of fatigue.

Complete data for baseline and follow-up evaluation were available in five boys (mean age $12.6 \pm 3.3$ years, hemoglobin $7.87 \pm 0.67 \mathrm{mmol} / \mathrm{L}$, and hematocit $36.4 \pm 0.02 \%$ ) who completed an average of 22 sessions. The hemodialysis duration of the patients was between 3 and $4 \mathrm{~h} /$ session (mean $3.47 \pm 0.51 \mathrm{~h}$ ) three times per week. No differences were found for baseline measurements between patients who did and did not complete the exercise program. Baseline and post training measurements are shown in Table $1 . \dot{V} \mathrm{O}_{2 \text { peak }} / \mathrm{kg}$, $\mathrm{W}_{\text {peak }}$, and total muscle strength tended to be higher after the exercise program. No obvious changes in HRQoL were observed. The three patients that filled out the CIS-20 showed a decreased perceived fatigue after the exercise program. Two patients were unable to fully understand the questions in this questionnaire.

\section{Discussion}

This is the first study reporting the feasibility and efficacy of a community-based exercise training program to improve exercise capacity and fatigue level in children with ESRD. The exercise program's success was hampered by the large number of patients who did not complete the program.
Seven patients did not complete or even start the program because of a combination of lack of time and motivational problems. Due to the time spent on the dialysis sessions, they were not sufficiently motivated to spend their leisure time two times a week on an exercise training program. A recent study shows that children on dialysis (HD or PD) have to spend $30 \%$ more of their after-school time on selfcare/household tasks compared with transplanted children [3]. Moreover, for the children on HD, transportation 3 days every week to a dialysis unit for a 3- to 4-h dialysis session is a tremendous burden. Being on dialysis requires a lot of time. Physical activity is probably not a first priority for these patients, and thus even exercise training before or after dialysis sessions have been quite unsuccessful [10]. Therefore, all reasons for not completing the program could be attributed directly and indirectly to the underlying illness.

An exercise program for healthy children should consist of at least two sessions of 30-60 min a week, with a total program duration of 6-16 weeks [11]. Several studies that describe exercise programs with beneficial results in adults with ESRD are in line with these recommendations. Although the intensity and duration of the exercise programs in adult studies vary, it is recommended to exercise at least three times per week [4]. In this respect, a decrease in the exercise frequency in our program would not be appropriate and would definitely decrease the effects, although it may increase adherence.

Almost $50 \%$ of the dropout was directly linked to the disease itself (medical reasons and transplantation) and seemed to be unavoidable. This shows that exercise training is difficult to perform in children with ESRD and seems difficult in real-life situations for many children with ESRD.

Comparable exercise programs in other chronic conditions that we performed, such as in osteogenesis imperfecta and cerebral palsy were not characterized by such a high dropout rate $[12,13]$. These children have a significant disability, although without a high disease actuality as in children with ESRD. 
Despite the limited feasibility, there were patients in whom a significant improvement in $\dot{V} \mathrm{O}_{2 \text { peak }} / \mathrm{kg}$ and muscle strength could be achieved following exercise training. In conclusion, different than in adults, exercise training is difficult to perform in children with ESRD and is not always feasible in real-life situations for many children with ESRD.

Acknowledgements This study was funded by a grant from the Dutch Kidney Foundation (grant \#KI30). We thank the children, parents, and trainers for their participation in this study.

Open Access This article is distributed under the terms of the Creative Commons Attribution Noncommercial License which permits any noncommercial use, distribution, and reproduction in any medium, provided the original author(s) and source are credited.

\section{References}

1. Eijsermans RM, Creemers DG, Helders PJ, Schroder CH (2004) Motor performance, exercise tolerance, and health-related quality of life in children on dialysis. Pediatr Nephrol 19:1262-1266

2. Weaver DJ Jr, Kimball TR, Knilans T, Mays W, Knecht SK, Gerdes YM, Witt S, Glascock BJ, Kartal J, Khoury P, Mitsnefes MM (2008) Decreased maximal aerobic capacity in pediatric chronic kidney disease. J Am Soc Nephrol 19:624-630

3. Painter P, Krasnoff J, Mathias R (2007) Exercise capacity and physical fitness in pediatric dialysis and kidney transplant patients. Pediatr Nephrol 22:1030-1039
4. Johansen KL (2005) Exercise and chronic kidney disease: current recommendations. Sports Med 35:485-499

5. ATS Committee on Proficiency Standards for Clinical Pulmonary Function Laboratories (2002) Ats statement: guidelines for the six-minute walk test. Am J Respir Crit Care Med 166:111-117

6. Engelbert RH, Plantinga M, Van der Net J, Van Genderen FR, Van den Berg MH, Helders PJ, Takken T (2008) Aerobic capacity in children with hemophilia. J Pediatr 152:833-838 838.e1

7. Beenakker EA, van der Hoeven JH, Fock JM, Maurits NM (2001) Reference values of maximum isometric muscle force obtained in 270 children aged 4-16 years by hand-held dynamometry. Neuromuscul Disord 11:441-446

8. Vercoulen J, Alberts M, Bleijenberg G (1999) De checklist individual strength (cis). Gedragstherapie 32:131-136

9. Wulffraat N, van der Net JJ, Ruperto N, Kamphuis S, Prakken BJ, Ten Cate R, Van Soesbergen RM, Van Rossum MA, Raat H, Landgraf JM, Kuis W (2001) The dutch version of the childhood health assessment questionnaire (chaq) and the child health questionnaire (chq). Clin Exp Rheumatol 19:S111-S115

10. Molsted S, Eidemak I, Sorensen HT, Kristensen JH (2004) Five months of physical exercise in hemodialysis patients: effects on aerobic capacity, physical function and self-rated health. Nephron Clin Pract 96:c76-c81

11. Edouard P, Gautheron V, D'Anjou MC, Pupier L, Devillard X (2007) Training programs for children: Literature review. Ann Readapt Med Phys 50:510-519, 499-509

12. Verschuren O, Ketelaar M, Gorter JW, Helders PJ, Uiterwaal CS, Takken $\mathrm{T}$ (2007) Exercise training program in children and adolescents with cerebral palsy: a randomized controlled trial. Arch Pediatr Adolesc Med 161:1075-1081

13. Van Brussel M, Takken T, Uiterwaal CS, Pruijs HJ, Van der Net J, Helders PJ, Engelbert RH (2008) Physical training in children with osteogenesis imperfecta. J Pediatr 152:111-116 